\title{
Agglomeration of cellulose nanocrystals: the effect of secondary sulfates and their use in product separation
}

\author{
Christoph Metzger (D) David Auber · Stephan Dähnhardt-Pfeiffer • \\ Heiko Briesen (i)
}

Received: 19 June 2020/ Accepted: 19 September 2020/Published online: 9 October 2020

(C) The Author(s) 2020

\begin{abstract}
This study was aimed at the development of a better understanding of the agglomeration behavior of sulfated cellulose nanocrystals (CNCs) in the presence of sulfates with monovalent $\left(\mathrm{NH}_{4}{ }^{+}\right.$, $\left.\mathrm{K}^{+}, \mathrm{Na}^{+}\right)$and divalent $\left(\mathrm{Ca}^{2+}\right)$ cations, and to demonstrate their potential in simple and efficient product separation. Protonated CNCs were counterion-exchanged and their ionic strength was increased by adding sulfates of the respective cation to trigger agglomeration. The critical concentrations of agglomeration (CAC) and peptization (CPC) were determined. We found that the agglomeration behavior of CNCs could be attributed to matching affinities between the cations and the sulfate half-ester groups on the CNC surfaces. Based on these findings, a facile and efficient downstream process was designed to separate CNCs from neutralized reactant solutions using $\mathrm{CAC}$ and $\mathrm{CPC}$. This method provides
\end{abstract}

Electronic supplementary material The online version of this article (https://doi.org/10.1007/s10570-020-03476-0) contains supplementary material, which is available to authorized users.

C. Metzger $(\square) \cdot$ D. Auber $\cdot$ H. Briesen

Chair of Process Systems Engineering, TUM School of Life Sciences Weihenstephan, Technical University of Munich, Munich, Germany

e-mail: christoph.metzger@tum.de

S. Dähnhardt-Pfeiffer

Microscopy Services Dähnhardt GmbH, Plambeckskamp

2, 24220 Flintbek, Germany colloidally stable CNCs at high yield provided by centrifugation. When salt concentrations in the product are maintained below the CAC, as prepared CNCs from neutralized reactant solutions might be used in hydrogels and emulsions.

Keywords Cellulose nanocrystals - Agglomeration · Peptization $\cdot$ Colloidal behavior $\cdot$ UV-Vis $\cdot$ Separation efficiency

\section{Introduction}

Cellulose nanocrystals (CNCs) are nanorods with widths ranging from 3 to $50 \mathrm{~nm}$ and aspect ratios from 5 to 50 (ISO 2017b). They have received an increasing amount of attention from academia and industry alike due to their straightforward production and their remarkable physical and chemical properties, which make them high-performance building blocks for a wide range of potential commercial applications (Cowie et al. 2014; Thomas et al. 2018; Dufresne 2019). CNCs are commonly produced by sulfuric acid-catalyzed hydrolysis of purified cellulosic feedstock extracted from botanical sources, tunicates, or bacteria (Habibi et al. 2010; Sacui et al. 2014), although numerous extraction methods exist (Trache et al. 2017). Hydrolytic cleavage of glycosidic linkages and further breakdown of cellulose to glucose and 
oligosaccharides, as well as conversion to 5-(hydroxymethyl)furfural preferably occurs in the amorphous domains of cellulose (Sun et al. 2016), leaving CNCs with higher acid resistance as the product. The morphology and yield of CNCs for a process are mainly determined by processing temperature, time, and the cellulose source (Beck-Candanedo et al. 2005; Dong et al. 2016). Concurrent with the hydrolysis, sulfate half-esters $\left(R-\mathrm{O}-\mathrm{SO}_{3}{ }^{-}\right)$are grafted onto some of the hydroxy sites of the CNCs. The number density of surface sulfate groups can be controlled by acid concentration and the acid-to-cellulose ratio (Dong et al. 2016; Abitbol et al. 2018). The electric surface charge governs electrostatic interparticle repulsion forces and thus the colloidal stability of CNCs in polar media. CNCs produced by sulfuric acid-catalyzed hydrolysis usually contain between 240 and $330 \mathrm{mmol}$ of sulfate per $\mathrm{kg}$ of CNCs (Dong et al. 1996; Araki et al. 1999).

Never-dried CNC colloids and counterion-exchanged CNCs $\left(\mathrm{H}^{+} \rightarrow \mathrm{Na}^{+}\right)$are commonly used for subsequent processing, as well as to produce new materials incorporating CNCs. Thus, a significant effort has been made to understand and to tune their colloidal stability. Several works have addressed the effect of electrolytes and ionic species on the agglomeration and gelation behavior of colloidal CNCs (Dong et al. 1996; Dong and Gray 1997; Boluk et al. 2011; Shafiei-Sabet et al. 2014; Cherhal et al. 2015; Peddireddy et al. 2016; Phan-Xuan et al. 2016; Bertsch et al. 2017; Mikhailov et al. 2017; Wu et al. 2017, 2019; Liu et al. 2018; Moud et al. 2018, 2019; Qi et al. 2019). All of the aforementioned studies focused on agglomeration of sulfated CNCs induced by chlorides, with inorganic counterions of varying valence. Studies have shown that the critical agglomeration concentration (CAC) of a volume of an electrolyte is in the range of tens of $\mathrm{mM}$ and decreases to a few $\mathrm{mM}$ with increasing valence of the counterion, roughly following the Schulze-Hardy rule (PhanXuan et al. 2016).

Agglomeration of CNCs also plays a role in downstream processing when CNCs are separated from the reactant solution that also contains sulfuric acid, the previously mentioned byproducts formed by hydrolysis, and incompletely hydrolyzed cellulosic residues. However, the unit operations involved have received only little attention. Hydrolysis of cellulose in a solution volume is usually quenched by adding a ten-fold amount of water (Trache et al. 2017). CNCs are then present in an agglomerated state due to the prevalently high ionic strength and cannot form a stable colloid. This agglomeration facilitates the removal of any excess ions and soluble reaction products by repeated washing by centrifugation and decanting of the supernatant, and subsequent redispersion in fresh water. In the presence of only sulfate anions, the critical peptization concentration (CPC) is approached at about $100 \mathrm{mM}$ sulfuric acid when peptization of the CNCs occurs, recognizable by an accruing cloudiness of the supernatant. Subsequent washing steps at ionic strengths below the CPC would imply a loss of colloidally stable product fractions in the discarded supernatant. Thus, any further purification of the intermediate product involves low-efficiency techniques such as dialysis or reverse osmosis, or it requires special apparatus, for example for diafiltration or electrodialysis (Rudie 2017).

In scale-up scenarios, $\mathrm{CNC}$ production may involve neutralization of the remaining acid with caustic soda after centrifugation (Reiner and Rudie 2013; Assis et al. 2017). Alternatively, the reactant solution can be neutralized with mono- or divalent hydroxides or metal oxides at an arbitrary step in downstream processing (Müller and Briesen 2017, Metzger et al. 2018). By analogy with product separation from diluted reactant solutions, ionic residues must be thoroughly removed from neutralized reactant solutions to obtain a colloidally stable product.

To date, studies of salt-induced agglomeration of CNCs have only addressed the use of chlorides to control the product properties, while the roles of salt and ionic residues during product separation have received no attention to our knowledge. In this study, we hypothesize that CNCs will show similar agglomeration behavior in the presence of sulfates as they do with chlorides. We therefore presume that it is not only ionic strength but also the type of cation that contributes to the colloidal stability of CNCs. Because the separation efficiency by centrifugation is directly related to colloidal stability, we assumed that the introduction of cations during neutralization of the intermediate product affects the CPC. Therefore, neutralization can be used to reduce the effort to purify the product.

The colloidal stability of sulfated $\mathrm{CNCs}$ in the presence of the secondary sulfates $\left(\mathrm{NH}_{4}\right)_{2} \mathrm{SO}_{4}, \mathrm{~K}_{2} \mathrm{SO}_{4}$, $\mathrm{Na}_{2} \mathrm{SO}_{4}$, and $\mathrm{CaSO}_{4}$ was investigated in this work by a 
fast and easy-to-use spectrophotometric method. The results were applied to design an efficient purification process based on the CAC and the CPC during centrifugation, yielding colloidally stable CNCs. The results are of particular interest for the sustainable production of $\mathrm{CNCs}$ with low resource requirements in downstream processing steps.

\section{Materials and methods}

\section{Chemicals}

Whatman ashless filter aids (cotton $\alpha$-cellulose) were purchased from Sigma-Aldrich (Taufkirchen, Germany). Calcium hydroxide $\left(\mathrm{Ca}(\mathrm{OH})_{2}, 96 \%\right)$, sulfuric acid $\left(\mathrm{H}_{2} \mathrm{SO}_{4}, 96 \%\right)$, potassium hydroxide $(\mathrm{KOH}$, $85 \%)$, ammonium hydroxide $\left(\mathrm{NH}_{4} \mathrm{OH}, 25 \%\right)$, and sodium hydroxide $(\mathrm{NaOH}, 99 \%)$ were used for preparing and processing $\mathrm{CNCs}$ and were purchased from Carl Roth (Karlsruhe, Germany). Poly-L-lysine (0.1\% (aq), Ted Pella, Redding, CA, USA), ethanol (70\%, Carl Roth, Karlsruhe, Germany), and uranyl acetate (SERVA, Heidelberg, Germany) were used for transmission electron microscopy. Sodium chloride $(\mathrm{NaCl}, 99.5 \%)$ and sodium hydroxide $(\mathrm{NaOH}(\mathrm{aq})$, $2 \mathrm{mM}$ ), required for conductometric titration, were purchased from Carl Roth. All chemicals were used in their as-received state. Ultrapure (type 1) water $\left(\mathrm{H}_{2} \mathrm{O}\right)$ with a resistivity of $18.2 \mathrm{M} \Omega \mathrm{cm}$ (Milli-Q Direct 8 system, Merck Chemicals, Schwalbach, Germany) was used to prepare solutions for all experiments.

\section{Preparation and processing of CNCs}

Aqueous colloidal suspensions of sulfated CNCs were prepared by heterogeneous hydrolysis of oven-dried $\left(105{ }^{\circ} \mathrm{C}, 30 \mathrm{~min}\right)$ cellulose with sulfuric acid, based on the method of Cranston and Gray (2006). The bound water content of the cellulosic feedstock after drying was determined to be $4.5 \mathrm{wt} \%$ by Karl Fischer titration, and was considered when calculating the weighed portions of the educts. Sulfuric acid, $96 \mathrm{wt} \%$ was diluted to $64.2 \mathrm{wt} \%$ with water and pre-heated to $45{ }^{\circ} \mathrm{C}$. Cellulose was added in at a mass-mixing ratio of $10 m_{\mathrm{H}_{2} \mathrm{SO}_{4}} m_{\text {cellulose }}^{-1}$ with the weighed portions of sulfuric acid, $m_{\mathrm{H}_{2} \mathrm{SO}_{4}}$, and cellulose, $m_{\text {cellulose }}$, and stirred constantly for $45 \mathrm{~min}$.
The agglomeration behavior of $\mathrm{CNCs}$ in the presence of secondary sulfates was studied in CNCs which were separated by centrifugation and dialysis (route A), as commonly reported in literature. The neutralization-based separation of $\mathrm{CNCs}$ by centrifugation (route $\mathrm{B}$ ) was conducted to demonstrate the applicability of the results from route A. Both routes were implemented in this work as illustrated in the flowcharts in Fig. 1. A detailed description of the unit operations involved in both routes, as well as further treatment of the CNCs prior to subsequent analyses, is given in the following sections.

\section{Route A: Product separation from diluted reactant solutions}

After hydrolysis, the reactant solution was quenched by tenfold dilution with regard to the effective initial acid concentration $\left(64 \rightarrow 6.4 \mathrm{wt} \%\right.$ ) with $4{ }^{\circ} \mathrm{C}$ water. Excess acid and soluble byproducts were decanted after leaving the precipitate to settle overnight. The resultant cloudy suspension was washed by twofold centrifugation for $15 \mathrm{~min}$ at $4500 \times g$ (Centrifuge 5804 R, Eppendorf, Hamburg, Germany), decanting, and further dilution with water. The precipitate was then dialyzed in regenerated cellulose tubes with a molecular weight cutoff of 12-14 kDa (ZelluTrans/ ROTH T3, Carl Roth, Karlsruhe, Germany) against running water with a volumetric flow of $0.5 \mathrm{~L} \mathrm{~h}^{-1}$ in a $7 \mathrm{~L}$ vessel to remove the remaining acid and soluble byproducts. Dialysis was stopped when the waste water had a conductivity $\leq 30 \mu \mathrm{S} \mathrm{cm} \mathrm{cm}^{-1}$ after equilibration for $6 \mathrm{~h}$. Agglomerated CNCs were disagglomerated by sonication with a homogenizer (Sonopuls HD 3400 with the sonotrode VS $70 \mathrm{~T}$, Bandelin, Berlin, Germany) at an energy input of $5 \mathrm{~kJ} \mathrm{~g}^{-1}$ cellulose and an amplitude setting of $30 \%$ in an ice bath. In accordance with Beck et al. (2011), no breakage of covalent cellulose-sulfate half-ester bonds - and thus no release of sulfate ions-was assumed due to sonication. Incompletely hydrolyzed solid cellulosic residues were then removed by centrifugation for $15 \mathrm{~min}$ at $4500 \times g$. Any further treatment with ion-exchange resins was omitted due to the extensive dialysis (Abitbol et al. 2013). The final dispersion of never-dried protonated $\mathrm{CNCs}$, denoted as $\mathrm{H}-\mathrm{CNC}$, was stored at $4{ }^{\circ} \mathrm{C}$ until further use.

To study salt-induced agglomeration, H-CNCs were first neutralized as separate samples by the 


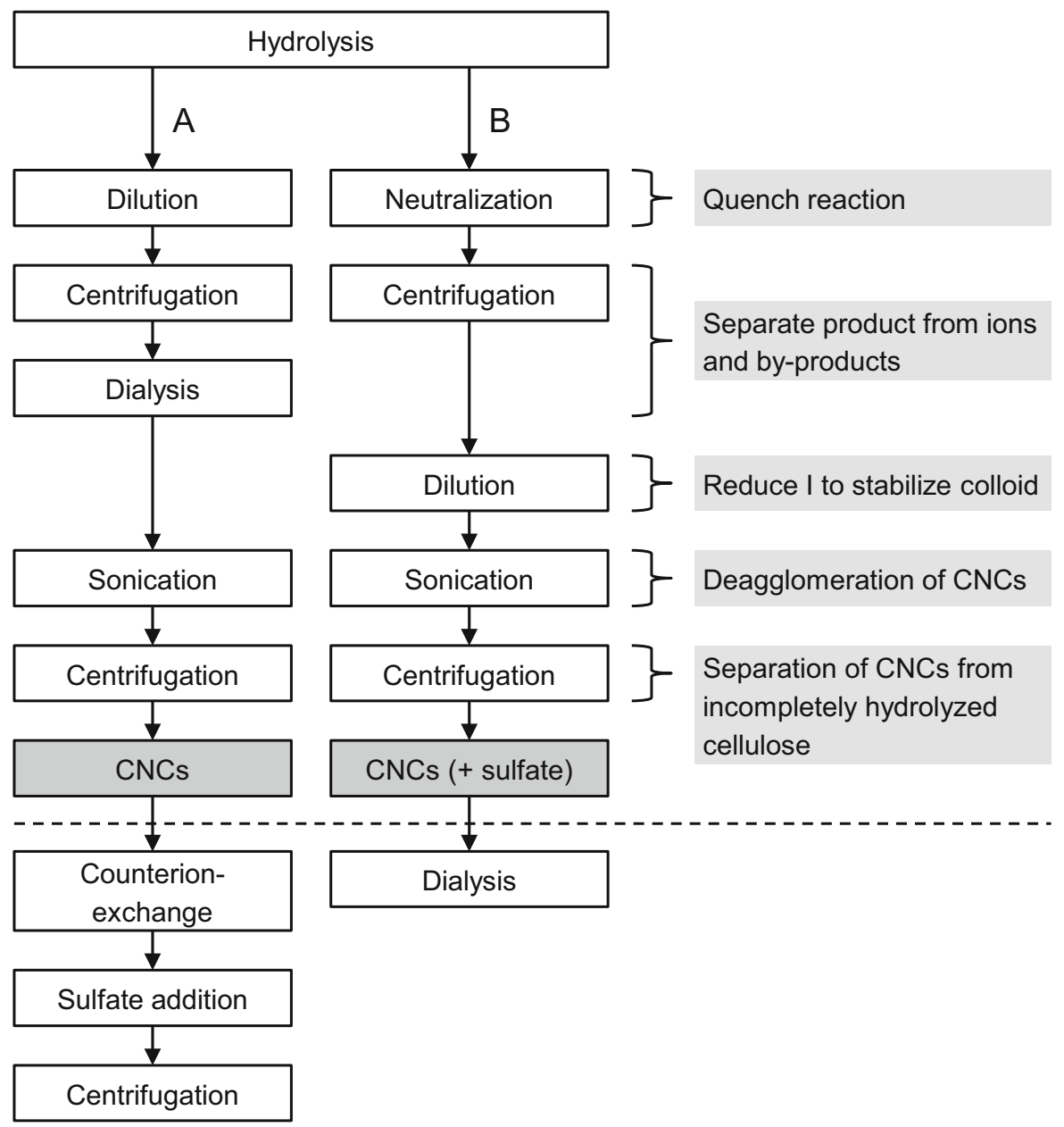

Fig. 1 Downstream processes for the purification of CNCs by centrifugation/dialysis (a) and neutralization/centrifugation (b). Further sample treatments for studying the agglomeration

addition of the respective base until a stable $\mathrm{pH}$ of 7 was reached. The samples were named in accordance with the respectively exchanged counterion $\mathrm{NH}_{4}{ }^{+}$, $\mathrm{K}^{+}, \mathrm{Na}^{+}$, or $\mathrm{Ca}^{2+}$ (Table 1). Then, the CAC, at which behavior and for determining the dispersion properties of the $\mathrm{CNCs}$ are presented below the dashed line

agglomeration is initially observed, and the CPC, at which all $\mathrm{CNCs}$ are agglomerated, were empirically determined using a binary search approach. For this approach, the ionic strengths, $I$, of aliquots of each

Table 1 Nomenclature of CNCs by the respective counterions and properties of the associated secondary sulfates

\begin{tabular}{llll}
\hline Sample & Counterion & Associated sulfate salt & Salt solubility $^{\text {a }} / \mathrm{g} \mathrm{L}^{-1}$ \\
\hline $\mathrm{H}-\mathrm{CNC}$ & $\mathrm{H}^{+}$ & & 754 \\
$\mathrm{NH}_{4}-\mathrm{CNC}$ & $\mathrm{NH}_{4}^{+}$ & $\left(\mathrm{NH}_{4}\right)_{2} \mathrm{SO}_{4}$ & 111 \\
$\mathrm{~K}-\mathrm{CNC}$ & $\mathrm{K}^{+}$ & $\mathrm{K}_{2} \mathrm{SO}_{4}$ & 170 \\
$\mathrm{Na}-\mathrm{CNC}$ & $\mathrm{Na}^{+}$ & $\mathrm{Na}_{2} \mathrm{SO}_{4}$ & 2 \\
$\mathrm{Ca}-\mathrm{CNC}$ & $1 / 2 \mathrm{Ca}^{2+}$ & $\mathrm{CaSO}_{4}$ & \\
\hline
\end{tabular}

${ }^{\mathrm{a}}$ At $20{ }^{\circ} \mathrm{C}$; data retrieved from the GESTIS substance database: gestis-en.itrust.de 
sample were adjusted by adding aqueous solutions of the secondary sulfate. In accordance with the literature (Cherhal et al. 2015), agglomeration at higher salt concentrations occurred instantly for all salts and was visible to the unaided eye. Destabilized CNCs would settle out over time (Cherhal et al. 2015), but the fraction of colloidally stable $\mathrm{CNCs}, \varphi_{s}$, was separated by centrifugation for $15 \mathrm{~min}$ at $4500 \times g$ and optical absorbance was used to quantify $\varphi_{s}$. The ionic strength of each sample was then adjusted in 15 steps from the CAC to the CPC. The salt solutions had been previously prepared by mixing the respective bases with sulfuric acid. The CNC concentration was kept constant at $1 \mathrm{wt} \%$ throughout the experiments.

\section{Route B: Product separation from neutralized reactant solutions}

Partial quantities from the same batch that was used to produce the $\mathrm{H}-\mathrm{CNCs}$ were separated after hydrolysis and the reaction was stopped by incremental neutralization with $\mathrm{NH}_{4} \mathrm{OH}, \mathrm{KOH}, \mathrm{NaOH}$, or $\mathrm{Ca}(\mathrm{OH})_{2}$ to an excess of $15 \%$ of the initial sulfuric acid. For this operation, the reactant solutions were transferred to an ice bath to compensate for the neutralization enthalpy and were incrementally neutralized with their respective ice-cold base solutions. The concentration of bases with mono- and divalent cations was $1.25 \mathrm{M}$ and $0.65 \mathrm{M}$, respectively. The intermediate products with monovalent cations were then washed by centrifugation for $15 \mathrm{~min}$ at $4500 \times \mathrm{g}$, decanted to remove the supernatant, and successively redispersed in fresh water to remove excess ions and soluble byproducts from the hydrolyzed product. Each sample was then neutralized to a $\mathrm{pH}$ of 7 with its respective base. In the $\mathrm{CaSO}_{4}$ sample, the salt concentration exceeded its maximum solubility. Enough water and base were added to fall below the CAC after the first washing step. The pellet, including precipitated $\mathrm{CaSO}_{4}$ and entrained CNCs, was discarded. All samples were subsequently diluted to a salt concentration of 1.1 CPC and centrifuged again. The supernatant was decanted and the precipitate was diluted to 0.9 CAC using water. Similar to route A, all samples were eventually sonicated, centrifuged again, and stored at $4{ }^{\circ} \mathrm{C}$ until further use. Quantities of each sample were dialyzed to compare their dispersion properties to $\mathrm{CNCs}$ from route $\mathrm{A}$.

\section{Instrument measurements}

All measurements were performed at least in triplicate and are presented with the $95 \%$ confidence interval of the mean. The uncertainty of quantities depending on multiple variables is driven by the propagation of error.

\section{Conductometric titration}

The content of the protonated sulfate half-esters $(R-$ $\mathrm{OSO}_{3} \mathrm{H}$ ) of the CNCs was determined by conductometric titration (Konduktometer 703 with the electrode sensor SE 204, Knick, Berlin, Germany) at $23{ }^{\circ} \mathrm{C}$, based on the method proposed by Beck et al. (2015). $5 \mathrm{~mL}$ of a $1 \mathrm{wt} \% \mathrm{CNC}$ dispersion was diluted into $80 \mathrm{~mL}$ of water. $1 \mathrm{~mL}$ of $0.1 \mathrm{M} \mathrm{NaCl}(\mathrm{aq})$ was added to elevate the conductivity to a measurable level. $2 \mathrm{mM} \mathrm{NaOH} \mathrm{(aq)} \mathrm{was} \mathrm{used} \mathrm{as} \mathrm{titrant} \mathrm{in} 0.2 \mathrm{~mL}$ increments under constant stirring. Stable conductivity readings were recorded $30-60 \mathrm{~s}$ after each addition.

The volume-corrected conductivity values were plotted against the added volume of $\mathrm{NaOH}$. The equivalence volume of $\mathrm{NaOH}$ needed, and thus the number of accessible sulfate groups, was calculated from the intersection of the least squares regression lines of the two linear branches $\left(R^{2} \approx 1\right)$ of the titration curve.

The conductivity of the waste water was also measured during dialysis (see Supporting Information).

Dry weight and yield calculations

The concentrations of dry constituents at different stages of production were calculated from the mass quotient of an aliquot before water evaporation, $m_{\text {wet }}$, and after water evaporation, $m_{d r y}$, by lyophilization (2-4 LSCplus, Christ, Osterode am Harz, Germany). Acidic aliquots were neutralized to a $\mathrm{pH}$ of 7 by titration against $\mathrm{NaOH}$ before water evaporation, and the weight of the formed salt, $m_{\text {salt }}$, was considered in order to calculate the concentration of the cellulosic fraction. The cellulosic fraction of a sample of weight, $m_{\text {sample }}$, was then extrapolated from the aliquot's concentration. The yield refers to $m_{\text {cellulose }}$, considering the overall mass balance and losses of individual 
unit operations. The yield, $Y$, of cellulosic solid residues after centrifugation is:

$Y=\frac{m_{\text {dry }}-m_{\text {salt }}}{m_{\text {wet }}} \cdot \frac{m_{\text {sample }}}{m_{\text {cellulose }}}$

The cellulose-to-CNC conversion rate was calculated from the ratio of the dry mass after dialysis and the dry mass after dialysis, sonication, and centrifugation.

Concentration adjustments were performed by diluting the stock dispersions with the respective amount of water.

\section{Dynamic and electrophoretic light scattering}

The hydrodynamic apparent particle size of dispersed CNCs was measured by dynamic light scattering (DLS) using a Zetasizer Nano ZSP (Malvern Instruments, Worcestershire, UK) equipped with a red laser $(633 \mathrm{~nm})$ under a backscatter detection angle of $173^{\circ}$. The harmonic intensity-weighted average particle diameter (z-avg) and the polydispersity index (PdI) from the cumulants analysis were obtained according to ISO 22412 (2017a) for $0.025 \mathrm{wt} \% \mathrm{CNC}$ dispersions after equilibration for $30 \mathrm{~min}$ at $25{ }^{\circ} \mathrm{C}$ in disposable polystyrene cuvettes.

The $\zeta$ potential is derived from the electrophoretic mobility of the CNCs, which was determined from electrophoretic light scattering (ELS) with the same instrument as above. $0.25 \mathrm{wt} \% \mathrm{CNC}$ dispersions were analyzed after equilibration for $30 \mathrm{~min}$ at $25^{\circ} \mathrm{C}$ in folded capillary cells (DTS1070). Smoluchowski behavior with $f(\kappa a)=1.5$ was assumed for Henry's function, where $\kappa$ was the Debye length and $a$ the particle radius.

\section{Transmission electron microscopy}

Pioloform-coated copper grids (G2440C) from Plano (Wetzlar, Germany) were incubated with $0.1 \%$ polyL-lysine at $23{ }^{\circ} \mathrm{C}$ for $30 \mathrm{~min}$, rinsed with water, and dried under dust-free atmosphere. Never-dried CNCs were diluted with $\mathrm{H}_{2} \mathrm{O}$ to a concentration of $0.025 \mathrm{wt} \%$ and homogenized in a low-intensity ultrasonic bath for $10 \mathrm{~min}$ before droplets of the suspension were applied to the grids with a pipette. After $20 \mathrm{~min}$, the grids were rinsed with water and left for drying. Negative staining of the CNCs was performed with a saturated ethanolic uranyl acetate solution. Excess liquid was removed and the samples were dried again. Transmission electron microscopy (TEM) images were acquired with a Philips CM10 instrument, coupled with a CCD camera (IDS, Obersulm, Germany), at an acceleration voltage of $80 \mathrm{kV}$. Particle length $L$ was evaluated from 66 randomly chosen, individual particles using ImageJ (Rasband 2018).

\section{$\mathrm{UV}-\mathrm{Vis}$ spectrophotometry}

Cellulose has no conjugated or unsaturated bonds. Hence, the optical absorption of transmitted light in the forward direction $\left(180^{\circ}\right)$ is 0 and the absorbance is governed by scattering only. For non-absorbing particles, the specific absorbance $A$ at infinite dilution of colloidally stable CNCs, $c_{C N C} \rightarrow 0$, is

$\left(\frac{A}{c_{C N C}}\right)_{0}=k \lambda^{-n}$

with the scattering coefficient $k$, the wavelength $\lambda$, and the wavelength exponent $n$ (Heller et al. 1962). $k$ is a function of $a$ and the relative refractive indices of the particles $\mu_{2}$ and the dispersant $\mu_{1} . n$ is a function of $a$ and can be derived from the slope of $\ln \left(A c_{C N C}^{-1}\right)$ versus $\ln \lambda$.

For non-spherical particles, the scattering cross sections and therefore the equivalent radii $a_{e q}$ can be represented by the radii of spheres with equivalent volume-to-surface-area ratios (Grenfell and Warren 1999). The size parameter

$x=\frac{2 \pi a_{e q}}{\lambda}$

of the CNCs being not significantly smaller than 1 over the scanned wavelength range indicates Mie scattering, while Rayleigh scattering can be ignored. This was confirmed on absorbance spectra with $a_{e q}$ derived from TEM data and wavelength-dependent refractive index data of cellulose from Sultanova et al. (2009), modeled with MiePlot (Laven 2018).

Thus, a linear relationship between the specific absorbance of a sample and the respective CNC concentration is observed. UV-Vis spectrophotometry is therefore suitable for the determination of the concentration of non-spherical colloidal CNCs with similar equivalent radii by using a comparison library of spectra of known CNC concentrations. A change of $a_{e q}$-for example induced by agglomeration, a change 
in polydispersity, or the use of particles of different dimensions-would manifest in a change of $n$. This establishes a validity criterion for the applicability of the library to the measurement data, but also limits its applicability for the determination of CNC concentration to particles of similar sizes only. The evaluation of the validity of measurement is shown in the Supplementary Information.

A library of the UV-Vis absorbance spectra was set up, consisting of 18 individual samples of $\mathrm{H}-\mathrm{CNCs}$ with defined concentrations between 0 and $1 \mathrm{wt} \%$. Aliquots of $1 \mathrm{~mL}$ were transferred to quartz glass cuvettes with an optical path length of $10 \mathrm{~mm}$ and spectra were recorded with a Specord 50 Plus spectrophotometer (Analytik Jena, Jena, Germany) in the wavelength range from 200 to $500 \mathrm{~nm}$. The CNC concentration of an arbitrary, water-dispersed sample could then be calculated from Eq. (2), for a sample concentration that is in the same concentration range as the library.

\section{Results and discussion}

H-CNCs from diluted reactant solution

$\mathrm{H}-\mathrm{CNCs}$ were produced by sulfuric acid-catalyzed hydrolysis of cellulose according to route A. A CPC of $115 \mathrm{mM} \mathrm{SO}_{4}{ }^{2-}$ of CNCs in the presence of residual sulfuric acid was empirically determined in a binary search. The yield of cellulosic solid residues after centrifugation was $46.2 \pm 0.6 \%$.

Further purification of the product was achieved by using dialysis. The conductivity of the waste water decayed exponentially to $30 \mu \mathrm{S} \mathrm{cm} \mathrm{cm}^{-1}$ after $166 \mathrm{~h}$ and the exchange of $83 \mathrm{~L}$ of water (see Supporting Information). CNCs were separated from incompletely hydrolyzed solid cellulosic residues by centrifugation subsequent to dialysis and sonication. The overall yield for cellulose-to-CNC conversion was $33.9 \pm 0.5 \%$.

Figure $2 \mathrm{a}$ is a representative TEM image of $\mathrm{H}$ CNCs. The number-weighted particle length distribution of H-CNCs ranged from 70 to $230 \mathrm{~nm}$ with a mean particle length $L_{\text {mean }}$ of $120 \mathrm{~nm}$ (Fig. 2b). Particle width $W$ was estimated to be $\leq 10 \mathrm{~nm}$ for the particles, yielding an aspect ratio of $\leq 25$ for all $\mathrm{H}-\mathrm{CNCs}$. The mean hydrodynamic apparent particle diameter of H-CNCs was $198 \pm 4 \mathrm{~nm}$.
Overestimation of the particle size by DLS in relation to the more accurate TEM evaluation can be explained by the presence of a minor fraction of strongly scattering larger particles (Jakubek et al. 2018). The $\mathrm{PdI}$ of $0.21 \pm 0.02$ suggests moderate polydispersity, in accordance with the TEM images.

The $\zeta$ potential of the H-CNCs was $-47.5 \pm 5.4 \mathrm{mV}$ and had a distribution width $\Delta \zeta$ of $7.8 \pm 1.2 \mathrm{mV}$. A sulfate half-ester content of $238 \pm 5 \mathrm{mmol} \mathrm{kg}^{-1}$ was determined by conductometric titration. Table 2 summarizes the results from cellulose hydrolysis and the most relevant properties of $\mathrm{H}-\mathrm{CNCs}$. The data is in accordance with literature values (Bondeson et al. 2006; Reid et al. 2017).

Salt-induced agglomeration of CNCs

Cation-specific agglomeration of $\mathrm{CNCS}$

by the addition of sulfate salts

Colloidally stable CNCs in the presence of salts form self-similar clusters as a function of the salt concentration (Cherhal et al. 2015; Phan-Xuan et al. 2016; Moud et al. 2018). Therefore, controlling the ionic species and the salt concentration provides control over colloidal stability and thus the agglomeration of CNCs.

Colloidal stability of counterion-exchanged CNCs was not impeded by minor salt additions, so the number fraction of colloidally stable $\mathrm{CNCs}$ remained constant until the salt concentration exceeded the CAC. As can be observed from Fig. 3a, the concentration of colloidally stable CNCs indeed did decline at salt concentrations above the CAC. The evolution of agglomeration with increasing salt concentration for every sulfate salt followed canonical colloidal behavior (Gregory 1976). Above the CPC, all CNCs were agglomerated and could be sedimented by centrifugation, leaving no colloidally stable $\mathrm{CNCs}$ in the supernatant. Both CAC and CPC follow the sequence $\mathrm{K}^{+}<\mathrm{Na}^{+}<\mathrm{NH}_{4}^{+}<\mathrm{Ca}^{2+}$.

All monovalent salts have similar interval widths of $\triangle \mathrm{CxC}=\mathrm{CPC}-\mathrm{CAC}$, and a comparatively narrower one for the salt with a divalent cation (Table 3). Each salt has a different CAC and CPC with regard to its ionic strength and therefore agglomeration cannot be explained by the screening of electrostatic surface charge alone (Fig. 3b). Monovalent cations do not follow Hofmeister's lyotropic series $\mathrm{NH}_{4}{ }^{+}<\mathrm{K}^{+}$ 

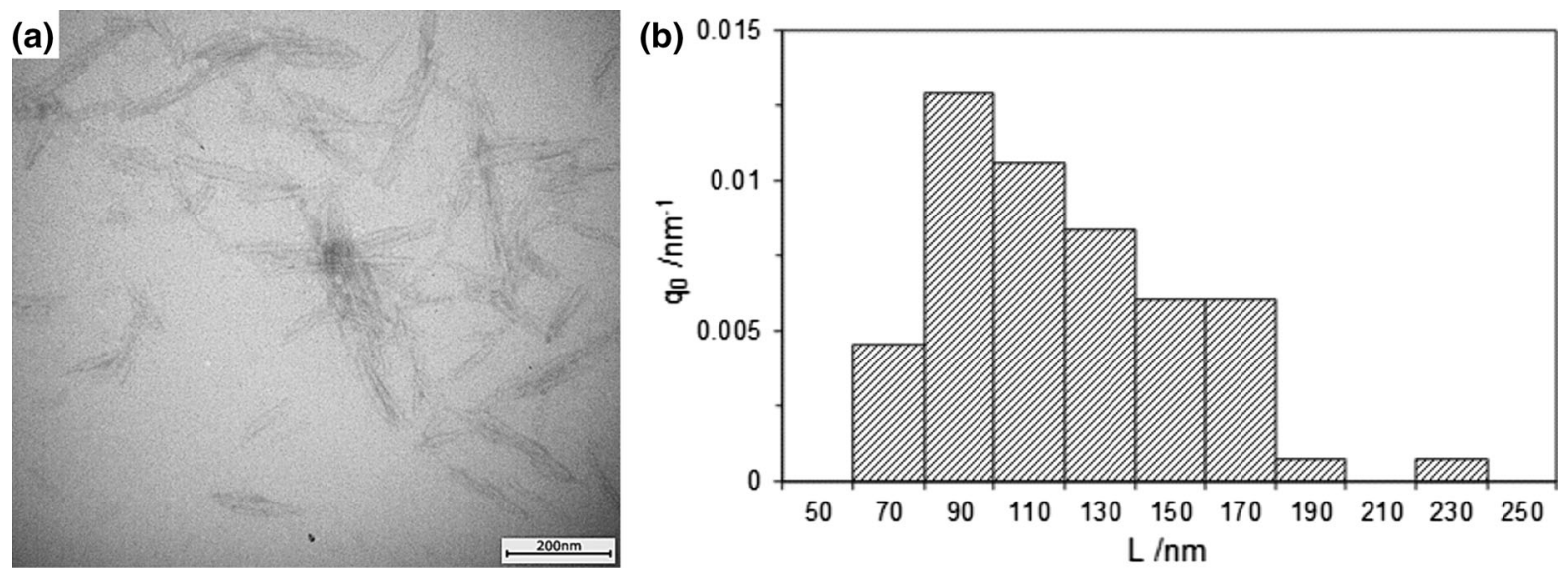

Fig. 2 TEM image of negatively stained H-CNCs (a) and number-weighted length distribution from 66 particles (b)

Table 2 Summary of hydrolysis and dispersion properties of H-CNCs

\begin{tabular}{llllll}
\hline Yield (solids) $(\%)$ & Yield $(\mathrm{CNCs})(\%)$ & $\mathrm{L}(\mathrm{TEM})(\mathrm{Nm})$ & $\mathrm{z}-\mathrm{avg}(\mathrm{nm})$ & $\zeta(\mathrm{mV})$ & \left.${\mathrm{c}\left(R-\mathrm{OSO}_{3}\right.}^{-}\right)\left(\mathrm{mmol} \mathrm{kg}^{-1}\right)$ \\
\hline $46.2 \pm 0.6$ & $33.9 \pm 0.5$ & $70-230$ & $198 \pm 4$ & $-47.5 \pm 5.4$ & $238 \pm 5$ \\
\hline
\end{tabular}
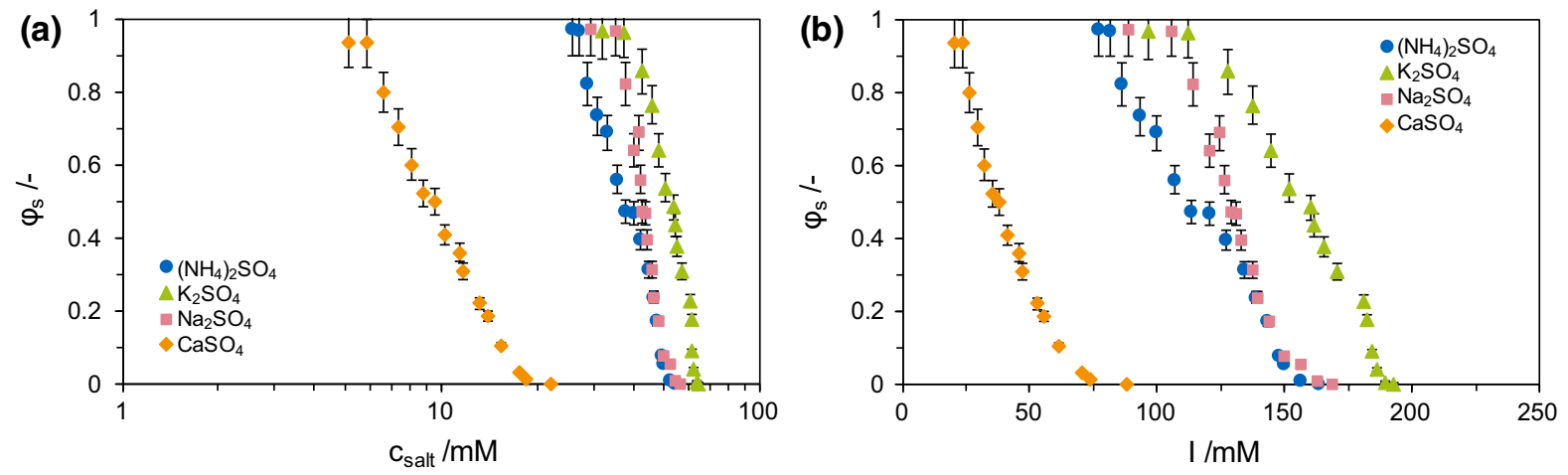

Fig. 3 Concentration of colloidally stable $\mathrm{CNCs}, \varphi_{s}$, as a function of salt concentration $c_{\text {salt }}$ (a) and ionic strength $I$ (b) for mono- and divalent secondary sulfates in separate aliquots having the same initial CNC concentration

Table 3 Critical concentrations and ionic strengths for agglomeration and peptization of CNCs in the presence of mono- and divalent secondary sulfates

\begin{tabular}{|c|c|c|c|c|c|c|c|c|c|}
\hline \multirow[t]{2}{*}{ Counterion } & \multicolumn{3}{|l|}{$\mathrm{CAC}$} & \multicolumn{3}{|l|}{$\mathrm{CPC}$} & \multicolumn{3}{|l|}{$\Delta \mathrm{CxC}$} \\
\hline & $\begin{array}{l}\mathrm{c} \\
(\mathrm{mM})\end{array}$ & $\begin{array}{l}\mathrm{I} \\
(\mathrm{mM})\end{array}$ & $\begin{array}{l}\mathrm{m}_{\text {salt }} \mathrm{m}_{\mathrm{CNC}}-1 \\
\left(\mathrm{mg} \mathrm{g}^{-1}\right)\end{array}$ & $\begin{array}{l}\mathrm{c} \\
(\mathrm{mM})\end{array}$ & $\begin{array}{l}\mathrm{I} \\
(\mathrm{mM})\end{array}$ & $\begin{array}{l}\mathrm{m}_{\text {salt }} \mathrm{m}_{\mathrm{CNC}}-1 \\
\left(\mathrm{mg} \mathrm{g}^{-1}\right)\end{array}$ & $\begin{array}{l}\mathrm{c} \\
(\mathrm{mM})\end{array}$ & $\begin{array}{l}\mathrm{I} \\
(\mathrm{mM})\end{array}$ & $\begin{array}{l}\mathrm{m}_{\text {salt }} \mathrm{m}_{\mathrm{CNC}}{ }^{-1} \\
\left(\mathrm{mg} \mathrm{g}^{-1}\right)\end{array}$ \\
\hline $\mathrm{NH}_{4}^{+}$ & 27 & 82 & 360 & 52 & 157 & 690 & 25 & 75 & 330 \\
\hline $\mathrm{K}^{+}$ & 37 & 112 & 650 & 63 & 189 & 1100 & 26 & 77 & 450 \\
\hline $\mathrm{Na}^{+}$ & 35 & 106 & 50 & 56 & 169 & 800 & 21 & 63 & 750 \\
\hline $\mathrm{Ca}^{2+}$ & 6 & 24 & 8 & 18 & 73 & 250 & 12 & 50 & 242 \\
\hline
\end{tabular}


$<\mathrm{Na}^{+}$(Hofmeister 1888). Furthermore, there is a marked difference in the agglomeration behavior of CNCs in the presence of a sulfate with a divalent cation with regards to its ionic strength. A tentative explanation of the deviation from DLVO theory of CNCs in the presence of salts has been proposed by Phan-Xuan et al. (2016). The differing magnitude of the impact of salts on the agglomeration of CNCs could be explained by the law of matching affinities (Vlachy et al. 2009). Soft cations in terms of charge density-such as $\mathrm{NH}_{4}^{+}$and $\mathrm{Ca}^{2+}$ - trigger earlier agglomeration of CNCs electrostatically stabilized by soft sulfate half-ester groups. The strong effect of $\mathrm{Ca}^{2+}$ on agglomeration could furthermore be induced by more intense clustering of CNCs in the presence of divalent salts, or could be initiated due to cross-linking of CNCs by multivalent cations (Wu et al. 2017; Moud et al. 2019).
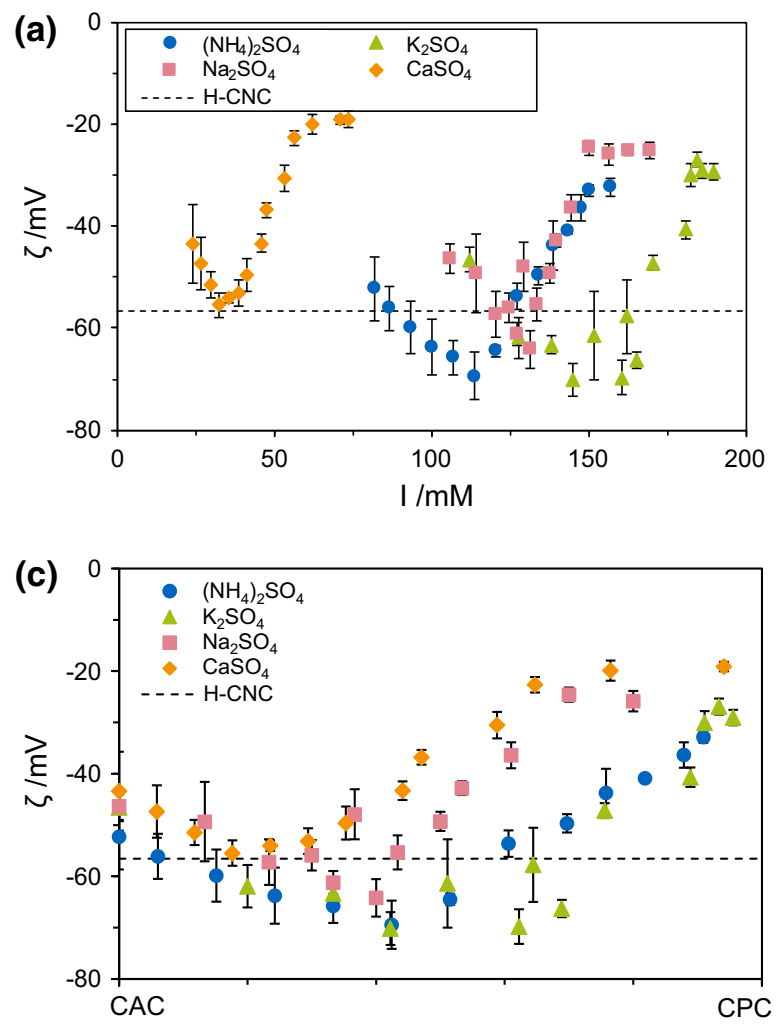

\section{Colloidal stability at different salt concentrations}

Figure 4a shows the evolution of the $\zeta$ potential of CNCs in the presence of sulfate salts with different cations between CAC and CPC. Adding a salt to sulfated CNCs promotes the screening of electrostatic charges and gel formation by particle agglomeration (Peddireddy et al. 2016; Moud et al. 2018). Thus, colloidal stability at the CAC was inferior to $\mathrm{H}-\mathrm{CNCs}$, manifesting in lower absolute $\zeta$ potentials in the presence of the sulfates. Soft cations showed an effect on colloidal stability at lower ionic strengths. The addition of sulfate salts in concentrations slightly above the CAC led to the precipitation of unstable clusters, which were sedimented by centrifugation and removed from the aliquots, as well as an increase in the absolute $\zeta$ potential of the colloidally stable particle fraction. The evolution of the $\zeta$ potential between CAC and CPC showed similar trends for all sulfates with increasing salt concentration; first, colloidal stability increased with increasing ionic strength, but

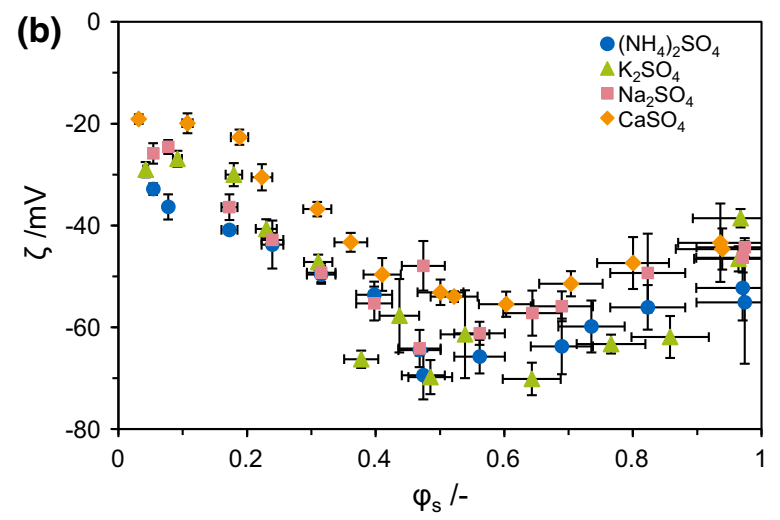

Fig. 4 Zeta potential of colloidally stable CNCs in the presence of mono- and divalent secondary sulfates as a function of ionic strength (a), as a function of the fraction of colloidally stable $\mathrm{CNCs} \varphi_{s}(\mathbf{b})$, and as normalized between CAC and CPC (c) 
then decreased to $|-20|-|-30| \mathrm{mV}$ towards the CPC (Fig. 4b, c). The highest absolute $\zeta$ potential for every salt was observed at $\varphi_{s} \approx 0.5$.

It must be noted that the stable CNC fraction was very small toward the CPC (compare to Fig. 3a, b). Considering the loss of CNCs, adding salts between the CAC and the CPC could enable fractionation of CNCs by their colloidal stability (see Supporting Information).

Figure 5 shows the hydrodynamic particle diameter of CNCs between CAC and CPC in the presence of sulfates having different cations. Increasing ionic strength has led to an overall higher z-avg compared to that of H-CNCs. This might be caused by the formation of denser clusters and elongated agglomerates due to an increasing number of contact points per particle (Moud et al. 2018). However, in our study, no correlation of hydrodynamic particle diameter and salt concentration or $\zeta$ potential was found. This result suggested that a weak cluster network with similar colloidal structures independent of the salt concentration, which has been observed by Moud et al. (2018) in $\mathrm{CNCs}$ in the presence of sodium chloride.

Efficiency of separation of CNCs from neutralized reactant solutions

The use of secondary sulfates for efficient CNC product separation by using the CAC and the CPC is demonstrated. For this purpose, the hydrolysis process was stopped by neutralizing the reactant solution with $\mathrm{NH}_{4} \mathrm{OH}, \mathrm{KOH}, \mathrm{NaOH}$, and $\mathrm{Ca}(\mathrm{OH})_{2}$. Washing steps were designed according to the CAC and the CPC, determined on $\mathrm{H}-\mathrm{CNCs}$ (route $\mathrm{B}$ ).

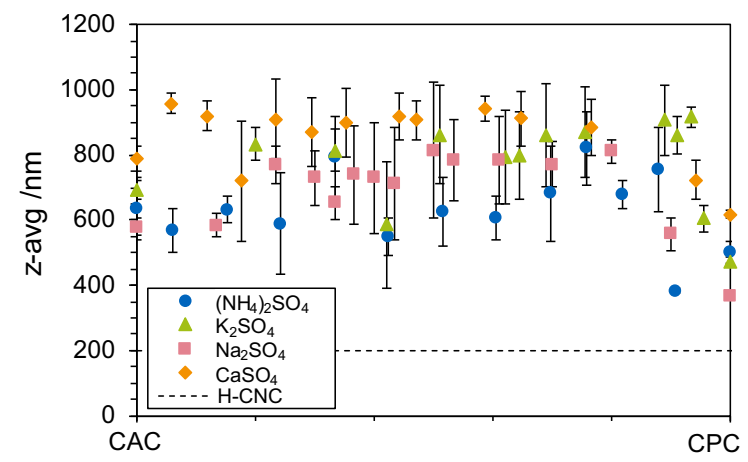

Fig. 5 Hydrodynamic apparent particle size (z-avg) of colloidally stable $\mathrm{CNCs}$ in the presence of mono- and divalent secondary sulfates, normalized between CAC and CPC
Salt solubility (Table 1), ionic strength at the CPC, and $\triangle \mathrm{CxC}$ determine the amount of water required during product separation (see Supporting Information). Accordingly, the final CNC concentration was highest for sulfates with monovalent cations (Table 4). Since the agglomeration behavior of CNCs does not depend on particle concentration (Phan-Xuan et al. 2016), the parameter that must be considered is the ionic strength at the CAC of the final CNC dispersion. Thus, by concentrating the intermediate sample, the method demonstrated here allows for higher final CNC concentrations and the salt-to-CNC ratio can be further reduced, yielding higher product purity.

Figure 6 shows the yield and colloidal properties of $\mathrm{H}-\mathrm{CNCs}$ compared to $\mathrm{CNCs}$ produced by route $\mathrm{B}$ using different base solutions for neutralization. To assess the colloidal properties under equivalent conditions, CNCs produced by route B were thoroughly dialyzed.

The yield of cellulose-to-CNC conversion was similar for each separation procedure involving sulfates with monovalent cations. The slightly lower yields of CNCs that were obtained from route B than for the production of $\mathrm{H}-\mathrm{CNCs}$ were attributed to product loss during manual sample handling. The significantly lower yield for neutralization with $\mathrm{Ca}(\mathrm{OH})_{2}$ was attributed to the loss of intermediate product with the precipitated salt. About $13 \%$ fewer sulfate half-ester groups per unit weight of CNCs were available for neutralized CNCs compared to H-CNCs. Thus, it was not possible to remove all counterions by dialysis; further deionization could be achieved by using a strong acid exchange resin (Abitbol et al. 2013). The lower concentration of accessible sulfate half-ester groups, in conjunction with the slightly greater hydrodynamic diameter, indicated the

Table 4 Concentration of colloidally stable CNCs in the product after neutralization and centrifugation, as well as the salt concentration, normalized to the relative salt-to-CNC mass ratio and the ionic strength

\begin{tabular}{llll}
\hline Counterion & $\mathrm{c}_{\mathrm{CNC}} / \mathrm{wt} \%$ & $\mathrm{~m}_{\text {salt }} \mathrm{m}_{\mathrm{CNC}}{ }^{-1} / \mathrm{g} \mathrm{g}^{-1}$ & $\mathrm{I} / \mathrm{mM}$ \\
\hline $\mathrm{NH}_{4}{ }^{+}$ & $1.675 \pm 0.026$ & $0.193 \pm 0.003$ & 18 \\
$\mathrm{~K}^{+}$ & $2.525 \pm 0.045$ & $0.233 \pm 0.004$ & 25 \\
$\mathrm{Na}^{+}$ & $2.254 \pm 0.074$ & $0.201 \pm 0.007$ & 13 \\
$\mathrm{Ca}^{2+}$ & $0.661 \pm 0.026$ & $0.111 \pm 0.004$ & 4 \\
\hline
\end{tabular}



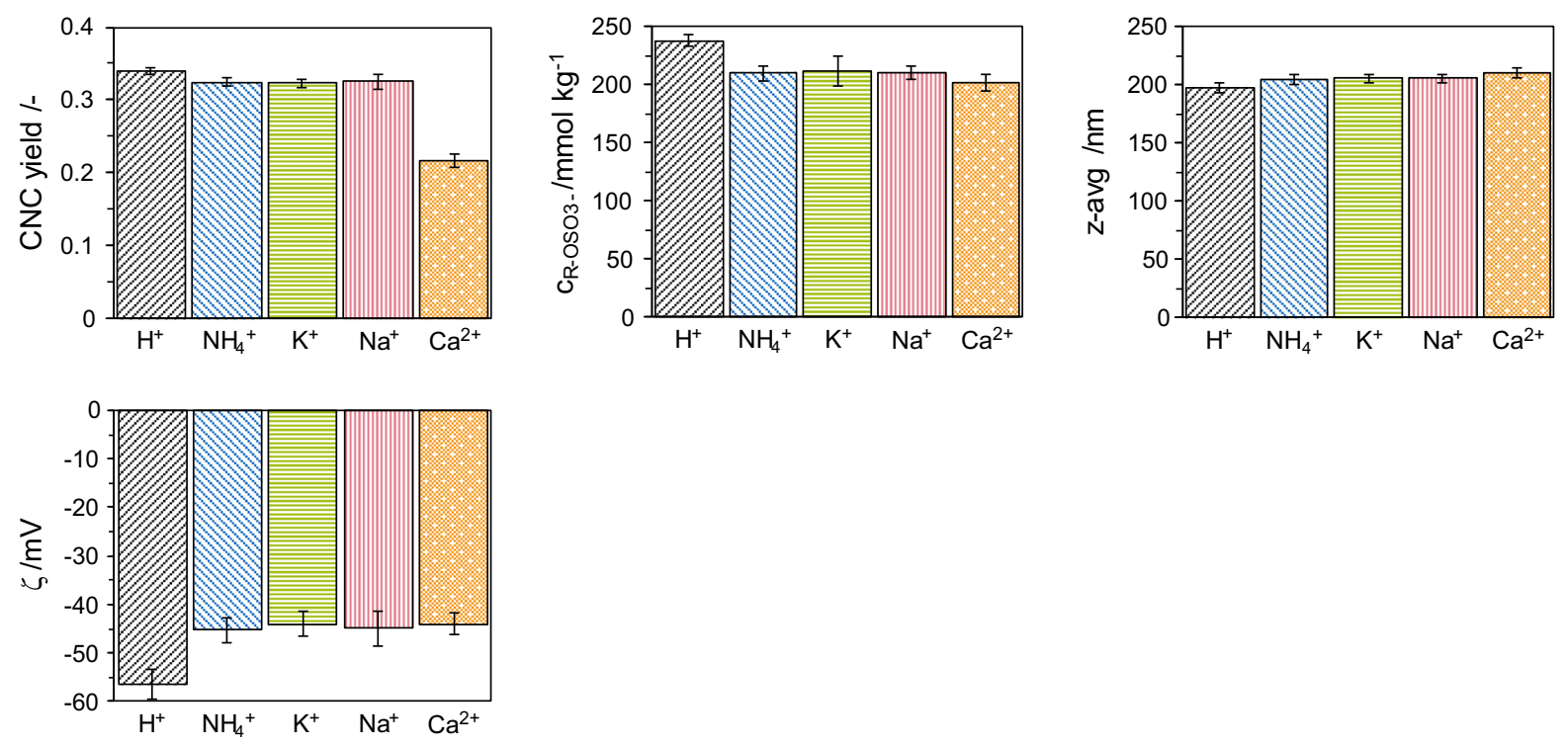

Fig. 6 Yield and dispersion properties of $\mathrm{H}-\mathrm{CNCs}$ in comparison to CNCs from neutralized and centrifuged reactant solutions

presence of $\mathrm{CNC}$ agglomerates which were not entirely broken up by sonication. Lower colloidal stability of CNCs as compared to H-CNCs was also reflected in the lower absolute $\zeta$ potential of $\mathrm{CNCs}$ from neutralized reactant solutions.

\section{Conclusions and outlook}

The agglomeration behavior of cellulose nanocrystals extracted from ashless cotton cellulose was studied in the presence of four secondary sulfates with monoand divalent cations from Groups 1 and 2 of the periodic table. An increase of ionic strength led to progressively greater agglomeration between the CAC and the CPC. Colloidal stability of CNCs was observed at salt concentrations below the CAC. No stable colloids formed at salt concentrations above the CPC. Both CAC and CPC varied among the different types of mono- and divalent cations. Therefore, agglomeration behavior is not attributable to electrostatic charge screening only and can be attributed to cluster formation and matching affinities. This result corroborates the hypothesis of similar agglomeration behavior of CNCs in the presence of sulfates as with that in the presence of chlorides. CAC and CPC were identified for each sulfate, and were applied in designing a neutralization-based downstream process.
Peptization of CNCs at decreasing ionic strengths limits the applicability of centrifugation for product separation after hydrolysis and dilution. Therefore, the CPC was shifted by introducing cations during neutralization of the reactant solution with $\mathrm{NH}_{4} \mathrm{OH}$, $\mathrm{KOH}, \mathrm{NaOH}$, and $\mathrm{Ca}(\mathrm{OH})_{2}$. Using both the $\mathrm{CAC}$ and the CPC for salt removal by successive centrifugation and dilution steps facilitated efficient separation of CNCs. The validity of the CAC and the CPC at higher $\mathrm{CNC}$ concentrations proves their independence of the CNC concentration. Thus, the process can be further improved to demand lower water consumption as well as lower consumption of other educts by first quenching the reaction with water, and then neutralizing the remaining acid after the first centrifugation.

When the added base formed a highly soluble sulfate salt, product yields were equal to those achieved for CNCs separated by dialysis. Any salt remaining in the product from neutralized solutions affected the dispersion properties of the CNCs; however, stable colloids were obtained. Reduction of the salt-to-cellulose ratio during centrifugation would enable lower salt concentrations in the product, by scaling the cellulosic portion. But dialyzing neutralized intermediate products did not result in fully protonated CNCs, and further purification might be accomplished through the use of ion-exchange resins. When ionic traces in the product are negligible for its use case, our process reduces the need for additional 
effort in product purification, since most sulfates are benign.

Knowledge about the CAC and the CPC could be used for fractionating CNCs by their colloidal stability. In the original never-dried state, the salt concentration can be adjusted to control the hydrogel structure. Last, intrinsically present counterions and salts promote redispersibility of dried $\mathrm{CNCs}$ and the stability of pickering emulsions (Beck et al. 2012; Missoum et al. 2012; Liu et al. 2018).

Acknowledgments The authors thank Michaela Thalhammer for her experimental contributions with Karl Fischer titrations. Moreover, we want to thank Johann Landauer for valuable discussions.

Authors' contributions CM and DA conceptualized and designed the study. Material preparation, data collection, and analysis were performed by CM, DA, and SDP. HB supervised the research. All authors contributed to the discussion and interpretation of results. The first draft of the manuscript was written by $\mathrm{CM}$, and all authors reviewed and edited the successive versions of the manuscript. All authors read and approved the final manuscript.

Funding Open Access funding enabled and organized by Projekt DEAL. The Chair of Process Systems Engineering did not receive any specific grant from funding agencies in the public, commercial, or not-for-profit sectors. Microscopy Services Dähnhardt $\mathrm{GmbH}$ has been funded by the Federal Ministry of Education and Research of Germany (BMBF) in the framework of the NanoCELL project within the funding initiative NanoCare 4.0 (Grant No 03XP196).

Data Availability The authors confirm that the data supporting the conclusions of this article are included within the article and its supplementary materials.

\section{Compliance with ethical standards}

Conflict of interest The authors declare that they have no conflict of interest.

Open Access This article is licensed under a Creative Commons Attribution 4.0 International License, which permits use, sharing, adaptation, distribution and reproduction in any medium or format, as long as you give appropriate credit to the original author(s) and the source, provide a link to the Creative Commons licence, and indicate if changes were made. The images or other third party material in this article are included in the article's Creative Commons licence, unless indicated otherwise in a credit line to the material. If material is not included in the article's Creative Commons licence and your intended use is not permitted by statutory regulation or exceeds the permitted use, you will need to obtain permission directly from the copyright holder. To view a copy of this licence, visit http://creativecommons.org/licenses/by/4.0/.

\section{References}

Abitbol T, Kloser E, Gray DG (2013) Estimation of the surface sulfur content of cellulose nanocrystals prepared by sulfuric acid hydrolysis. Cellulose 20(2):785-794

Abitbol T, Kam D, Levi-Kalisman Y, Gray DG, Shoseyov O (2018) Surface charge influence on the phase separation and viscosity of cellulose nanocrystals. Langmuir 34(13):3925-3933

Araki J, Wada M, Kuga S, Okano T (1999) Influence of surface charge on viscosity behavior of cellulose microcrystal suspension. J Wood Sci 45(3):258-261

de Assis CA, Houtman C, Phillips R, Bilek EM, Rojas OJ, Pal L, Peresin MS, Jameel H, Gonzalez R (2017) Conversion economics of forest biomaterials: risk and financial analysis of CNC manufacturing. Biofuels Bioprod Bioref 11(4):682-700

Beck S, Bouchard J, Berry R (2011) Controlling the reflection wavelength of iridescent solid films of nanocrystalline cellulose. Biomacromol 12(1):167-172

Beck S, Bouchard J, Berry R (2012) Dispersibility in water of dried nanocrystalline cellulose. Biomacromol 13(5): 1486-1494

Beck S, Méthot M, Bouchard J (2015) General procedure for determining cellulose nanocrystal sulfate half-ester content by conductometric titration. Cellulose 22(1):101-116

Beck-Candanedo S, Roman M, Gray DG (2005) Effect of reaction conditions on the properties and behavior of wood cellulose nanocrystal suspensions. Biomacromol 6(2):1048-1054

Bertsch P, Isabettini S, Fischer P (2017) Ion-induced hydrogel formation and nematic ordering of nanocrystalline cellulose suspensions. Biomacromol 18(12):4060-4066

Boluk Y, Lahiji R, Zhao L, McDermott MT (2011) Suspension viscosities and shape parameter of cellulose nanocrystals (CNC). Colloid Surf Physicochem Eng Aspects 377(1-3):297-303

Bondeson D, Mathew A, Oksman K (2006) Optimization of the isolation of nanocrystals from microcrystalline cellulose by acid hydrolysis. Cellulose 13(2):171-180

Cherhal F, Cousin F, Capron I (2015) Influence of charge density and ionic strength on the aggregation process of cellulose nanocrystals in aqueous suspension, as revealed by small-angle neutron scattering. Langmuir 31(20): $5596-5602$

Cowie J, Bilek EM, Wegner TH, Shatkin JA (2014) Market projections of cellulose nanomaterial-enabled productspart 2: volume estimates. TAPPI J 13(6):57-69

Cranston ED, Gray DG (2006) Morphological and optical characterization of polyelectrolyte multilayers incorporating nanocrystalline cellulose. Biomacromol 7(9):2522-2530

Dong XM, Gray DG (1997) Effect of counterions on ordered phase formation in suspensions of charged rodlike cellulose crystallites. Langmuir 13(8):2404-2409

Dong XM, Kimura T, Revol J-F, Gray DG (1996) Effects of ionic strength on the isotropic-chiral nematic phase transition of suspensions of cellulose crystallites. Langmuir 12(8):2076-2082

Dong S, Bortner MJ, Roman M (2016) Analysis of the sulfuric acid hydrolysis of wood pulp for cellulose nanocrystal 
production: a central composite design study. Industrial Crops Prod 93:76-87

Dufresne A (2019) Nanocellulose processing properties and potential applications. Curr Forestry Rep 5(2):76-89

Gregory J (1976) The effect of cationic polymers on the colloidal stability of latex particles. J Colloid Interface Sci 55(1):35-44

Grenfell TC, Warren SG (1999) Representation of a nonspherical ice particle by a collection of independent spheres for scattering and absorption of radiation. J Geophys Res 104(D24):31697-31709

Habibi Y, Lucia LA, Rojas OJ (2010) Cellulose nanocrystals: chemistry, self-assembly, and applications. Chem Rev 110(6):3479-3500

Heller W, Bhatnagar HL, Nakagaki M (1962) Theoretical investigations on the light scattering of spheres. XIII. The "wavelength exponent" of differential turbidity spectra. J Chem Phys, 36(5):1163-1170

Hofmeister F (1888) Zur Lehre von der Wirkung der Salze. Archiv f experiment Pathol u Pharmakol 24(4-5):247-260

ISO (2017a) ISO 22412:2017-Particle size analysis-Dynamic light scattering (DLS), 2017-02. International Organization for Standardization, Geneva, Switzerland. https://www.iso. org/standard/65410.html

ISO (2017b) ISO/TS 20477:2017-Nanotechnologies-standard terms and their definition for cellulose nanomaterial, 2017-10. International Organization for Standardization, Geneva, Switzerland. https://www.iso.org/standard/68153.html

Jakubek ZJ, Chen M, Couillard M, Leng T, Liu L, Zou S, Baxa U, Clogston JD, Hamad WY, Johnston LJ (2018) Characterization challenges for a cellulose nanocrystal reference material: dispersion and particle size distributions. J Nanopart Res, 20(4)

Laven P (2018) MiePlot 4.6-https://www.philiplaven.com/ mieplot.htm

Liu L, Hu Z, Sui X, Guo J, Cranston ED, Mao Z (2018) Effect of counterion choice on the stability of cellulose nanocrystal pickering emulsions. Ind Eng Chem Res 57(21):7169-7180

Metzger C, Sanahuja S, Behrends L, Sängerlaub S, Lindner M, Briesen H (2018) Efficiently extracted cellulose nanocrystals and starch nanoparticles and techno-functional properties of films made thereof. Coatings 8(4):142

Mikhailov VI, Torlopov MA, Martakov IS, Krivoshapkin PV (2017) Stability of nanocrystalline cellulose in aqueous $\mathrm{KCl}$ solutions. Colloid J 79(2):226-233

Missoum K, Bras J, Belgacem MN (2012) Water redispersible dried nanofibrillated cellulose by adding sodium chloride. Biomacromol 13(12):4118-4125

Moud AA, Arjmand M, Yan N, Nezhad AS, Hejazi SH (2018) Colloidal behavior of cellulose nanocrystals in presence of sodium chloride. ChemistrySelect 3(17):4969-4978

Moud AA, Arjmand M, Liu J, Yang Y, Sanati-Nezhad A, Hejazi SH (2019) Cellulose nanocrystal structure in the presence of salts. Cellulose 26:9387-9401

Müller V, Briesen H (2017) Nanocrystalline cellulose, its preparation and uses of such nanocrystalline cellulose. U.S. Patent 20170306056 A1

Peddireddy KR, Capron I, Nicolai T, Benyahia L (2016) Gelation kinetics and network structure of cellulose nanocrystals in aqueous solution. Biomacromol 17(10):3298-3304
Phan-Xuan T, Thuresson A, Skepö M, Labrador A, Bordes R, Matic A (2016) Aggregation behavior of aqueous cellulose nanocrystals: the effect of inorganic salts. Cellulose 23(6):3653-3663

Qi W, Yu J, Zhang Z, Xu HN (2019) Effect of pH on the aggregation behavior of cellulose nanocrystals in aqueous medium. Mater Res Express 6(12): 125078

Rasband W (2018) ImageJ 1.52h - https://imagej.nih.gov/ij/. $\mathrm{NIH}$

Reid MS, Villalobos M, Cranston ED (2017) Benchmarking cellulose nanocrystals: from the laboratory to industrial production. Langmuir 33(7):1583-1598

Reiner RS, Rudie AW (2013) Process scale-up of cellulose nanocrystal production to $25 \mathrm{~kg}$ per batch at the Forest Products Laboratory. In: Postek MT, Moon RJ, Rudie AW, Bilodeau M (eds) Production and applications of cellulose nanomaterials. TAPPI Press, Peachtree Corners, GA, USA, pp 21-24

Rudie A (2017) Commercialization of cellulose nanofibril (CNF) and cellulose nanocrystal (CNC): pathway and challenges. In: Kargarzadeh H, Ahmad I, Thomas S, Dufresne A (eds) Handbook of nanocellulose and cellulose nanocomposites, vol 1. Wiley-VCH. Weinheim, Germany, pp 761-797

Sacui IA, Nieuwendaal RC, Burnett DJ, Stranick SJ, Jorfi M, Weder C, Foster EJ, Olsson RT, Gilman JW (2014) Comparison of the properties of cellulose nanocrystals and cellulose nanofibrils isolated from bacteria, tunicate, and wood processed using acid, enzymatic, mechanical, and oxidative methods. ACS Appl Mater Interfaces 6(9):6127-6138

Shafiei-Sabet S, Hamad WY, Hatzikiriakos SG (2014) Ionic strength effects on the microstructure and shear rheology of cellulose nanocrystal suspensions. Cellulose 21(5):3347-3359

Sultanova N, Kasarova S, Nikolov I (2009) Dispersion properties of optical polymers. Acta Phys Pol A 116(4):585-587

Sun Y, Liu P, Liu Z (2016) Catalytic conversion of carbohydrates to 5-hydroxymethylfurfural from the waste liquid of acid hydrolysis NCC. Carbohydrate Polym 142:177-182

Thomas B, Raj MC, Athira KB, Rubiyah MH, Joy J, Moores A, Drisko GL, Sanchez C (2018) Nanocellulose, a versatile green platform: from biosources to materials and their applications. Chem Rev 118(24):11575-11625. https://doi. org/10.1021/acs.chemrev.7b00627

Trache D, Hussin MH, Haafiz MKM, Thakur VK (2017) Recent progress in cellulose nanocrystals: sources and production. Nanoscale 9(5):1763-1786

Vlachy N, Jagoda-Cwiklik B, Vácha R, Touraud D, Jungwirth P, Kunz W (2009) Hofmeister series and specific interactions of charged headgroups with aqueous ions. Adv Colloid Interface Sci 146(1-2):42-47

Wu Q, Li X, Fu S, Li Q, Wang S (2017) Estimation of aspect ratio of cellulose nanocrystals by viscosity measurement: influence of surface charge density and $\mathrm{NaCl}$ concentration. Cellulose 24(8):3255-3264

Wu Q, Li X, Li Q, Wang S, Luo Y (2019) Estimation of aspect ratio of cellulose nanocrystals by viscosity measurement: influence of aspect ratio distribution and ionic strength. Polymers 11(5):781

Publisher's Note Springer Nature remains neutral with regard to jurisdictional claims in published maps and institutional affiliations. 